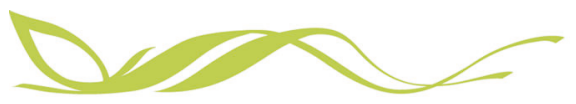

COMMUNICATIONS

EARTH\&ENMRONMENT

ARTICLE

https://doi.org/10.1038/s43247-020-00058-7

OPEN

\title{
Experimental reaction rates constrain estimates of ozone response to calcium carbonate geoengineering
}

Zhen Dai (i) $^{1 凶}$, Debra K. Weisenstein ${ }^{1}$, Frank N. Keutsch ${ }^{1,2}$ \& David W. Keith (1) ${ }^{1,3}$

Stratospheric solar geoengineering (SG) would impact ozone by heterogeneous chemistry. Evaluating these risks and methods to reduce them will require both laboratory and modeling work. Prior model-only work showed that $\mathrm{CaCO}_{3}$ particles would reduce, or even reverse ozone depletion. We reduce uncertainties in ozone response to $\mathrm{CaCO}_{3}$ via experimental determination of uptake coefficients and model evaluation. Specifically, we measure uptake coefficients of $\mathrm{HCl}$ and $\mathrm{HNO}_{3}$ on $\mathrm{CaCO}_{3}$ as well as $\mathrm{HNO}_{3}$ and $\mathrm{ClONO}_{2}$ on $\mathrm{CaCl}_{2}$ at stratospheric temperatures using a flow tube setup and a flask experiment that determines cumulative long-term uptake of $\mathrm{HCl}$ on $\mathrm{CaCO}_{3}$. We find that particle ageing causes significant decreases in uptake coefficients on $\mathrm{CaCO}_{3}$. We model ozone response incorporating the experimental uptake coefficients in the AER-2D model. With our new empirical reaction model, the global mean ozone column is reduced by up to $3 \%$, whereas the previous work predicted up to $27 \%$ increase for the same SG scenario. This result is robust under our experimental uncertainty and many other assumptions. We outline systematic uncertainties that remain and provide three examples of experiments that might further reduce uncertainties of $\mathrm{CaCO}_{3} \mathrm{SG}$. Finally, we highlight the importance of the link between experiments and models in studies of SG.

\footnotetext{
${ }^{1}$ John A. Paulson School of Engineering and Applied Sciences, Harvard University, Cambridge, MA 02138, USA. ${ }^{2}$ Department of Chemistry and Chemica Biology, Harvard University, Cambridge, MA 02138, USA. ${ }^{3}$ John F. Kennedy School of Government, Harvard University, Cambridge, MA 02138, USA.

凶email: zdai@g.harvard.edu
} 
$\mathrm{T}$ he deliberate introduction of aerosols into the stratosphere as a means of solar geoengineering (SG) might reduce some climate risks. Yet physical risks and efficacy of stratospheric aerosol geoengineering are poorly constrained due to uncertainty in the climate's response to aerosol radiative forcing and to local stratospheric processes that include stratospheric chemistry, heating, and aerosol microphysics. Uncertainties about local process can be reduced by experiments. A prior modeling study ${ }^{1}$ from our group suggested that calcium carbonate $\left(\mathrm{CaCO}_{3}\right)$ might enable stratospheric geoengineering with reduced ozone loss or even ozone increase, but that study lacked measurements of important $\mathrm{CaCO}_{3}$-specific reaction rates. It assumed that uptake coefficients (the probability that a gas-phase molecule is reactively bound following collision with a solid aerosol surface) of ozone-relevant gas species on $\mathrm{CaCO}_{3}$ is independent of the fraction of $\mathrm{CaCO}_{3}$ that been consumed in the reaction. This uncertainty needs to be resolved by empirical methods.

The use of empirical tools to study solar geoengineering has been limited. Field experiments are contentious ${ }^{2}$. Modeling studies use existing experimental results for sulfate, but there have been very few laboratory studies to address uncertainties of SG using non-sulfate particles ${ }^{3,4}$. This work is among the first efforts ${ }^{5}$ to measure uptake coefficients on solid particles at stratospheric temperatures. Our purpose is reducing uncertainty about SG.

Sulfate is the most widely-studied material for stratospheric SG because of the prominence of natural sulfate aerosols in the stratosphere and the long history exploring their links to climate ${ }^{6}$. In addition, there appear to be ways to inject $\mathrm{SO}_{2}$ and likely $\mathrm{H}_{2} \mathrm{SO}_{4}$ based on existing technologies ${ }^{7,8}$. However, sulfate aerosols pose well-known risks such as ozone depletion and stratospheric heating. $\mathrm{CaCO}_{3}$ particles have been proposed as an alternative to sulfate, and major motivations include the potential to reduce both risks ${ }^{1,9-12}$. This work addresses the ozone depletion aspect. Many modeling studies that explore chemical impacts of potential SG deployment have shown ozone depletion effects from a range of sulfate distribution scenarios, chiefly due to their impacts on $\mathrm{NO}_{\mathrm{x}}\left(\mathrm{NO}\right.$ and $\left.\mathrm{NO}_{2}\right)$ and halogen species ${ }^{13-16}$. These effects could counteract the recovery of ozone under the Montreal Protocol and increase risks of SG scenarios designed to mitigate impacts of climate change.

Non-sulfate materials have been proposed to address various risks of SG. Nearly two decades ago, Teller and Wood ${ }^{17}$ proposed the use of alumina nanoparticles based on scattering considerations while cautioning about environmental impacts. Other solid particles including $\mathrm{TiO}_{2}, \mathrm{SiC}, \mathrm{ZrO}_{2}$, diamond, and $\mathrm{CaCO}_{3}$ have been explored ${ }^{9-12}$. Diamond and alumina might reduce ozone depletion compared with sulfate when producing the same radiative forcing 18 .

$\mathrm{CaCO}_{3}$ produces much less stratospheric heating than does sulfate $^{18}$, and is a plausible material given the extensive industrial-scale manufacture of micron-scale calcite particles 1,19 . $\mathrm{CaCO}_{3}$ could also address the risks of ozone depletion by reactive uptake of acidic species containing halogens, sulfur, and nitrogen, effectively scrubbing ozone-depleting species from the stratosphere. However, due to the competition between denoxification and dehalogenation, it is difficult to know the net effect on ozone a priori.

One important shortcoming of Keith et al. ${ }^{1}$ is uncertainty of the uptake coefficients due to lack of experimental data. Here we measure the uptake coefficients of four reactions at stratospheric temperature:

$$
\begin{gathered}
\mathrm{CaCO}_{3}+\mathrm{HCl} . \\
\mathrm{CaCO}_{3}+\mathrm{HNO}_{3} .
\end{gathered}
$$

$$
\begin{gathered}
\mathrm{CaCl}_{2}+\mathrm{HNO}_{3} . \\
\mathrm{CaCl}_{2}+\mathrm{ClONO}_{2} .
\end{gathered}
$$

These reactions are important as they directly impact the chlorine and nitrate budget in the stratosphere, which critically affect stratospheric ozone concentration ${ }^{20}$. Eqs. (1) and (2) determine the capacity of $\mathrm{CaCO}_{3}$ to sequester $\mathrm{NO}_{\mathrm{x}}$ and halogen species, and Eq. (3) and Eq. (4) release reactive halogen species back to the stratosphere. We did not include heterogeneous reactions of gaseous $\mathrm{HBr}, \mathrm{BrONO}_{2}$ and $\mathrm{H}_{2} \mathrm{SO}_{4}$ with $\mathrm{CaCO}_{3}$ particles because Keith et al. showed that these reactions caused little change in background mixing ratios of $\mathrm{BrO}_{\mathrm{x}}$ or $\mathrm{H}_{2} \mathrm{SO}_{4}$. Uptake coefficients of Eqs. (1) and (2) have been experimentally determined, but not under stratospheric conditions ${ }^{21,22}$. Uptake coefficients of Eqs. (3) and (4) have not been studied previously. In addition, Keith et al. did not include heterogeneous catalysis on $\mathrm{CaCO}_{3}$ surfaces such as $\mathrm{ClONO}_{2}+\mathrm{HCl}$. Here we assess the potential impacts of these reactions. We find that exposure to gasphase acids causes $\mathrm{CaCO}_{3}$ particles to age rapidly, reducing their reactivity. This is in stark contrast to liquid sulfuric acid particles with surfaces that are unaffected by aging. We use these data to constrain a chemical transport model of stratospheric chemistry and aerosol microphysics and find that the prior model results overestimated ozone response.

\section{Results}

Experimental determination of uptake coefficients. Flow tube experiments have been widely used to study heterogeneous uptake coefficients for gas-solid reactions relevant to the stratosphere. For example, Molina et al. studied the uptake of $\mathrm{ClONO}_{2}$ on silica and alumina in the presence of $\mathrm{HCl}^{5}$. Davies and $\mathrm{Cox}^{23}$ studied the reaction between $\mathrm{HNO}_{3}$ and $\mathrm{NaCl}$. Schmidt et al. ${ }^{24}$ studied reaction between acetone and $\mathrm{TiO}_{2}$. Figure 1a shows the schematic of our flow tube experiment, it is similar to Molina et al. with slight modifications. We synthesized $\mathrm{ClONO}_{2}$ inline using plasmonic dissociation of $\mathrm{Cl}_{2}$ and cryogenically purified it inline (more details in the method section). As there are no literature values for the uptake coefficient of $\mathrm{ClONO}_{2}$ on $\mathrm{CaCl}_{2}$, we first compare our results for the uptake coefficients of $\mathrm{ClONO}_{2}$ on $\mathrm{NaCl}$ with existing literature values to validate our synthesis and measurement methods. The results confirm that our experimental and analysis approach as well as our $\mathrm{ClONO}_{2}$ synthesis method produce valid results: the uptake coefficient of $\mathrm{ClONO}_{2}$ on $\mathrm{NaCl}$ was determined to be $5 \pm 3 \times 10^{-3}$ at room temperature, which is close to the values reported in literature (Gebel et al. ${ }^{25}$ reported $\left.6.5 \pm 3 \times 10^{-3}\right)$.

Uptake coefficients were calculated using the method of Knopf et al. ${ }^{26}$ (details in the "method" section). Typical time series for an uptake experiment for Eqs. (1) and (4) are shown in Fig. 2a, b and more detailed uptake coefficients measured are shown in Table 1. Consistent with previous literature, the reactions all show large initial uptake which gradually decays to a slowly varying semi steady state value (uptake signal changes by $<5 \% / \mathrm{min}$ ). This process demonstrates a slow deactivation of the particles' reactivity for gaseous uptake reactions.

Uptake coefficients at the semi steady state are shown in Table 1. For Eq. (2), this level occurs after about $10 \mathrm{~min}$. Immediately after the insert is retracted upstream of the injector following the uptake experiment, a small increase in the $\mathrm{HCl}$ signal corresponding to reversibly adsorbed $\mathrm{HCl}$ on the surface is observed, consistent with the uptake experiment results in literature and the observation that $\mathrm{HCl}$ is reversibly adsorbed on the calcite surface before irreversible uptake occurs ${ }^{21}$. For Eq. (2), 
(a)

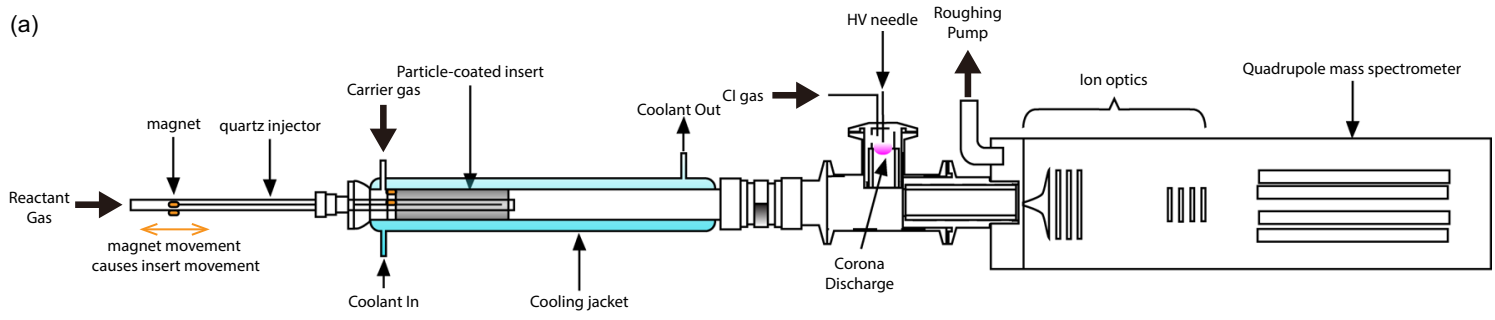

(b)

Chemical Reactions

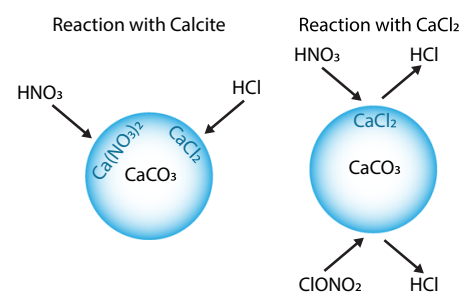

Physical Processes

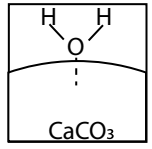

Water Adsorption

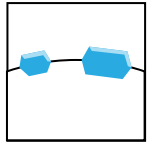

Crystallization

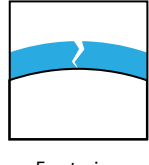

Fracturing

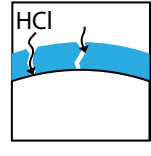

Diffusion

Fig. 1 Schematics of the experimental setup and some potentially important reaction processes. a Schematics of the flow tube and mass spectrometer used for the flow tube experiments. $\mathbf{b}$ Schematics of the important physical and chemical interactions during heterogeneous uptake of gaseous molecules.
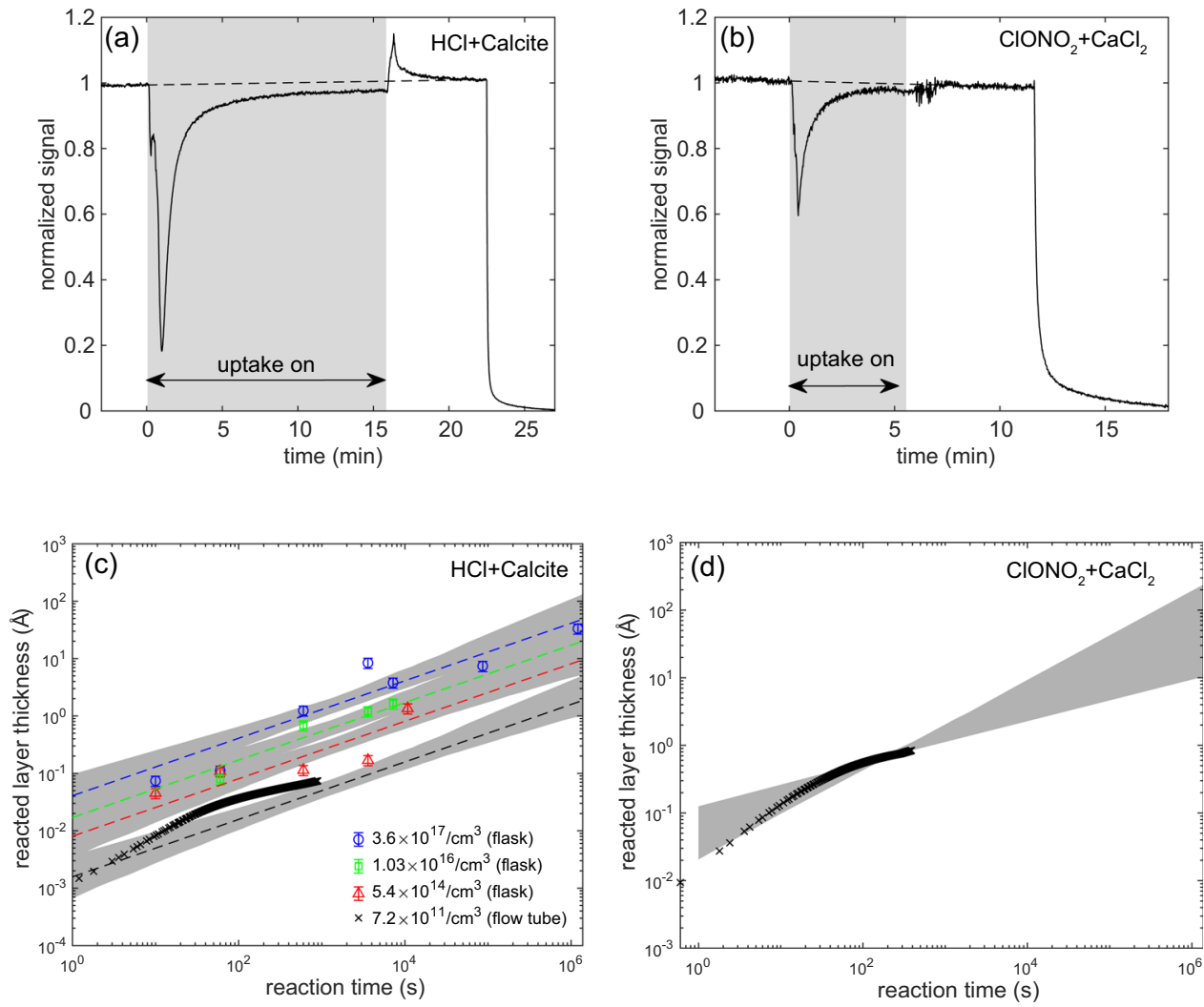

Fig. 2 Results from uptake experiments. a, b Typical uptake signal from the flow tube experiments for $\mathrm{HCl}+\mathrm{calcite}$ and $\mathrm{ClONO}_{2}+\mathrm{CaCl} 2$ reactions respectively. The baseline was subtracted and signal normalized to the background level. c, $\mathbf{d}$ Results from long-term uptake experiments and parametric fit results for $\mathrm{HCl}+\mathrm{Calcite}$ and $\mathrm{ClONO}_{2}+\mathrm{CaCl}_{2}$ respectively. Thickness-dependent uptake coefficients listed in Table 1 are extracted from these fits. Error bars in the data points in c represent systematic error from the experiment. Results from the mass spectrometer measurements are overlaid on the plots. The shadowed regions show $95 \%$ confidence intervals of the parametric fit extracted using bootstrapping as outline in the experimental section. The standard errors for fitting parameters $A$ and $n$ (defined in the text) are 0.18 and 0.05 , and the covariance is -0.08 .

the semi steady state level occurs after about $3 \mathrm{~min}$. In contrast to Eq. (2), there is no desorption peak after the insert is pulled upstream of the injector, signaling that this reaction proceeded without the adsorption step as in Eq. (2). For the $\mathrm{HNO}_{3}$ uptake reactions, the initial rapid changes in uptake could not be observed because there is a prominent time-varying background uptake by the quartz insert, while the background uptake of $\mathrm{HCl}$ and ClONO2 are smaller and did not show time-dependent 
Table 1 Parameterization of thickness-dependent uptake coefficients.

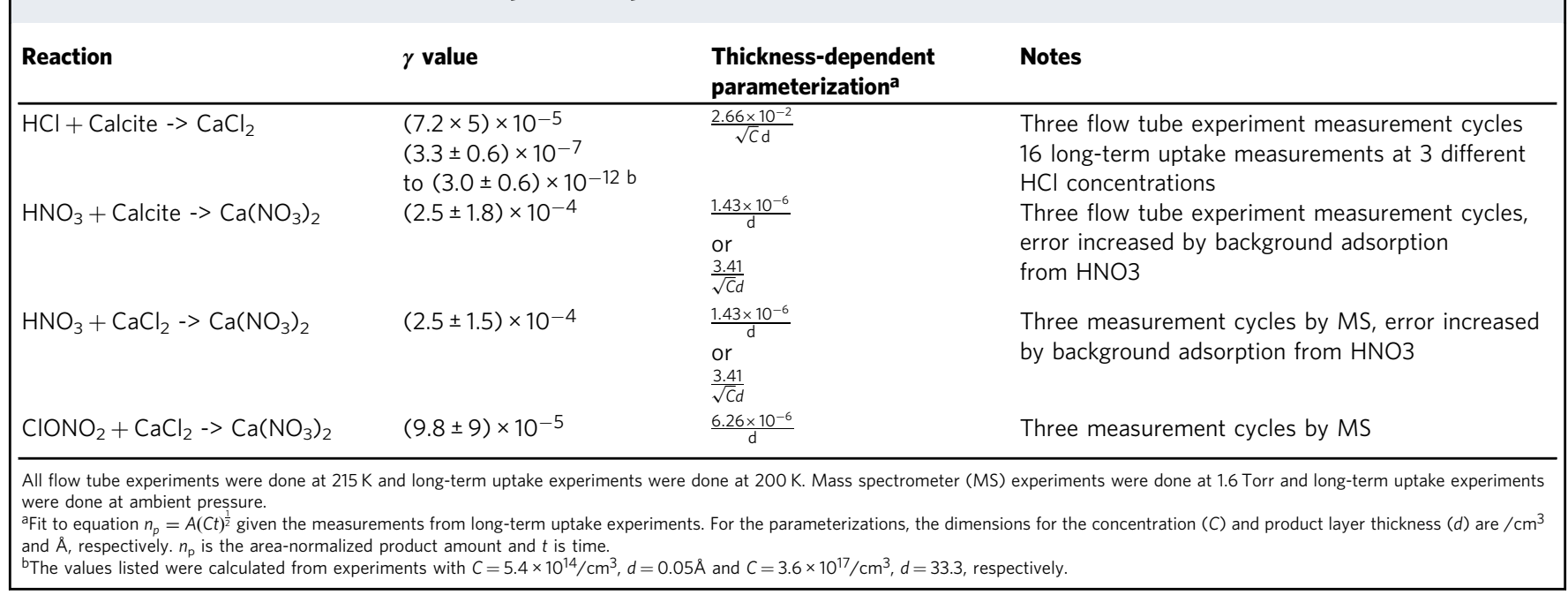

characteristics. We therefore did not extract the time-dependent uptake signal for these reactions as the case for Eq. (2) and (3), and calculated the semi steady-state uptake coefficient based on the difference in mass spectrometer (MS) signal between the background value and after the signal reaches a steady value.

Flow tube experiments measure rates of surface reactions but are not suited to explore continuous changes in the uptake coefficients after exposures on the order of days or weeks as the uptake signal decreases below the detection limit. To explore the long-duration regime we conducted a set of long-term uptake "flask experiments" to measuring reaction rates between $\mathrm{CaCO}_{3}$ particles and $\mathrm{HCl}$.

Flask experiments are conducted for Eq. (1) with three $\mathrm{HCl}$ concentrations, and the results are shown in Fig. 2c. The result from one flow tube experiment is also displayed for comparison. The concentrations span six orders of magnitude, and for each $\mathrm{HCl}$ concentration, we see that the reacted layer thickness growth rates decrease with reaction time, representing decreasing reactive uptake coefficients as a function of reaction extent.

Estimating thickness-dependent uptake coefficients. Unlike liquid sulfate particles, whose surface chemical composition are not affected by gas-phase uptake, $\mathrm{CaCO}_{3}$ particles age under gaseous exposure as products accumulate on their surfaces. As a result, the uptake coefficients change with exposure. We incorporate these changes by formulating uptake coefficients that depend on the product layer thickness and refer to them as thickness-dependent uptake coefficients. This is challenging because uptake coefficient changes are affected by many processes including the changes of available $\mathrm{CaCO}_{3}$ reaction sites as a function of reaction extent, adsorption and equilibration of water on the particle surface ${ }^{21}$, diffusion of gaseous species to available reaction sites, crystallization of reaction products ${ }^{27}$, and steric changes that might cause fractures in the product layer (schematics shown in Fig. 1b). Various empirical models were used to account for these changes including a shrinking-core model ${ }^{28}$, a Crystallization and Fracture modeling framework $^{29}$, a kinetic model ${ }^{30}$, and a surface solvation model ${ }^{31}$. None of these processes have been studied extensively under stratospheric conditions. We therefore posit a semi-empirical model that assumes that the gas phase uptake rate is proportional to the diffusion rate of reactive gaseous species through a surface product layer to reach available $\mathrm{CaCO}_{3}$ reaction sites. The physical intuition is that the reaction rate is dominated by a diffusion-like process where the availability of the reactant plays a dominant role after the initial surface product forms and slows further reaction. The corresponding form of the cumulative product per unit area is $n_{p}=A\left(C^{n} t\right)^{\frac{1}{2}}$, where $A$ is the fitting parameter to the empirical data, $C$ is the concentration of the gas phase reactive species, $t$ is time of reaction, and $n$ is an empirical constant chosen differently for various reactions based on their uptake mechanisms. As discussed in the experimental result section, Eq. (2) proceeds following an initial reversible surface adsorption and dissociation of $\mathrm{HCl}$ on $\mathrm{CaCO}_{3}$, and $\mathrm{n}$ was chosen as $1 / 2$, consistent with the argument of Huthwelker et al. ${ }^{32}$; Eq. (4) proceeds without the initial reversible adsorption, and $n$ was set to be 1 . For Eq. (2), 1/2 is also the best fit for the data when $\mathrm{n}$ floats in the fitting routine. The uptake mechanisms for Eqs. (2) and (3) are unknown, and we formulated the reactions based on both the 1/2th and 1st order assumptions. This expression of $n_{\mathrm{p}}$ was chosen as it parsimoniously captures the reaction and diffusion processes. The corresponding thicknessdependent parameterizations are shown in Table 1 . We selected this model because it fits our data well and is parsimonious (with only essential parameters to ensure low model variances) considering the high uncertainties due to various kinetic processes. We attempted a few other fitting models that are either more complicated or do not explain the experimental trends as well (Supplementary Fig. S1). The 95\% confidence interval shown in Fig. 2c, d are calculated using bootstrapping ${ }^{33}$ and shows higher error where data are sparse.

Modeling global ozone impact. We use a slightly updated version of the atmospheric chemistry model used in Keith et al. ${ }^{1}$, adopting the highest injection rate of $5.6 \mathrm{Tg} / \mathrm{yr} \mathrm{CaCO}_{3}$ from that analysis (see "method" section). In addition to the scenario using the full thickness-dependent parameterization (thk-dep) and the 2040 baseline scenario without solar geoengineering, we studied five other scenarios: (i) thk-ind, with thickness-independent uptake coefficient $(\gamma)$ values from the second column in Table 1, (ii) no psc, with the same $\gamma$ values as in the thk-dep case but with polar stratospheric clouds (PSC) reactions turned off, (iii) $0 \times \gamma$, with $\gamma$ values for Eqs. (1)-(4) set to 0, (iv) thk-dep + conc-dep, with thickness-dependent $\gamma$ values using the alternative concentration-dependent $\gamma$ values for Eqs. (2) and (3) (this captures uncertainties in the uptake mechanism of Eqs. (2) and (3) as described in the previous section), and (v) $10 \times \gamma$, with $\gamma$ values set to ten times the thk-dep case. The $0 \times \gamma$ and $10 \times \gamma$ scenarios capture the uncertainties of calcite particle surface area density since changing the uptake coefficient is equivalent to changing the surface area density available for gas-phase uptake. 

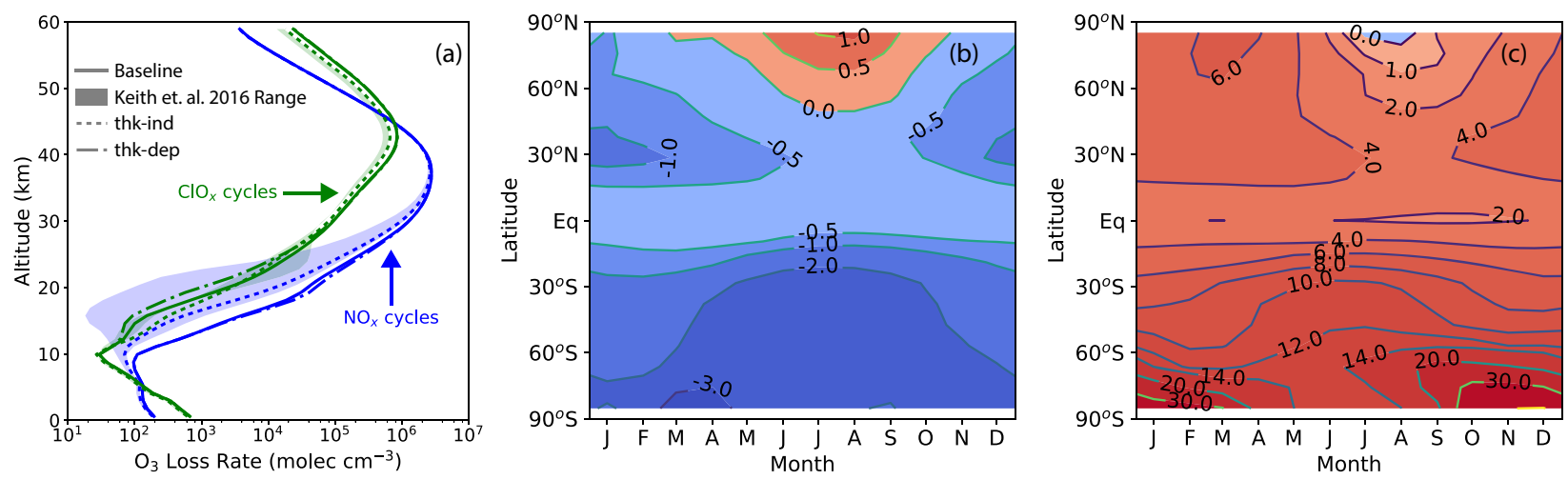

Fig. 3 Changes in important ozone depleting species and ozone compared with Keith et. al. ${ }^{\mathbf{1}}$ estimates. a Annually averaged rate of ozone loss caused by $\mathrm{NO}_{x}$ and $\mathrm{ClO}_{x}$ catalytic cycles as a function of altitude, averaged from $60^{\circ} \mathrm{S}$ to $60^{\circ} \mathrm{N}$. b Changes (percent) in ozone column estimates using the thk-dep parameterization compared with the baseline scenario with no solar geoengineering. Positive values indicate ozone increases. c Differences in ozone column estimates (percent) between the thk-ind scenario and the thk-dep scenario compared to the baseline outcomes. Positive values mean higher ozone estimates using the thk-ind parameterization.

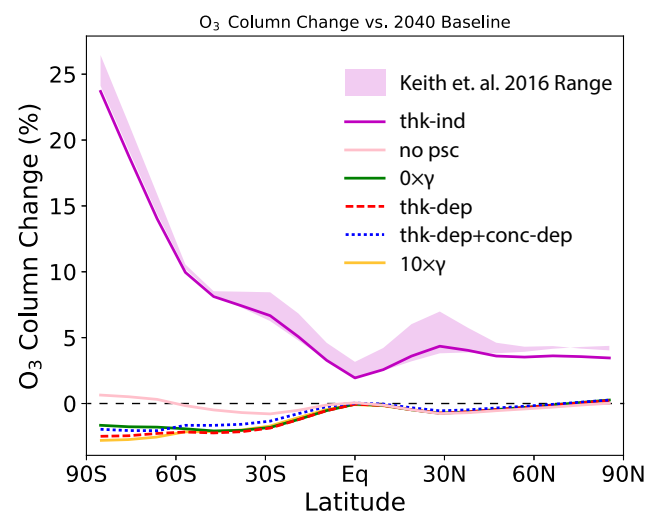

Fig. 4 Meridional ozone changes compared to 2040 baseline assuming various parameterizations of the uptake coefficients. The range of results obtained from Keith et al. ${ }^{1}$ are shown in the shaded region. These correspond to thickness-independent uptake coefficients for Eqs. (1)-(4) with values between $10^{-4}$ and 1 . In the case of ten times of the physical surface area $(10 \times \gamma)$, only heterogeneous reaction rates were varied, and not the physical coagulation processes.

Figure 3 shows the impact of $\mathrm{CaCO}_{3}$ emissions on ozone loss rates caused by important ozone depleting species compared with Keith et al. The $\mathrm{NO}_{\mathrm{x}}$ cycles play a much more important role than $\mathrm{ClO}_{\mathrm{x}}$ for all cases, and the thk-dep case shows an increase over the baseline in the $\mathrm{NO}_{\mathrm{x}}$-related loss rates in contrast to the results from the thk-ind scenario and Keith et al. This is consistent with the decrease in $\mathrm{ClO}$ and increase in $\mathrm{NO}_{\mathrm{x}}$ mixing ratio for the thkdep case in Supplementary Fig. S2. The impact on column ozone as a function of time and latitude is shown in Fig. 2b, c. The thkind scenario predicts an increase in ozone columns over the baseline similar to results from Keith et al., while the thk-dep scenario negates most of these increases.

Changes in important ozone depleting species and ozone are shown in Fig. 3, and annually averaged meridional ozone changes over the baseline from these scenarios are shown in Fig. 4. The thk-ind scenario results in a globally averaged column ozone increase of 5\%, while the thk-dep scenario shows a $1 \%$ decrease. For both cases, the largest ozone changes occur in the southern hemisphere. The thk-ind scenario shows column ozone increase of as high as $24 \%$, while the thk-dep scenario shows a much smaller change of up to $3 \%$ reduction.
This ozone change in the thk-dep scenario below the baseline are caused primarily by $\mathrm{NO}_{\mathrm{x}}$. As Fig. 3 shows, the changes in the $\mathrm{NO}_{\mathrm{x}}$ and $\mathrm{ClO}_{\mathrm{x}}$ cycles are smaller and in the opposite direction compared with the Keith et al. estimates, and the overall effect is a decrease in the ozone column compared to the baseline. Similarity between results from the thk-dep scenario and the $0 \times \gamma$ results show that these impacts are not caused by Eqs. (2)(4) but are predominantly caused by the decrease in background sulfate from neutralization by $\mathrm{CaCO}_{3}$ particles. This causes a decrease in $\mathrm{Cl}$ activation and $\mathrm{ClO}$ concentration, which in turn results in less $\mathrm{ClONO}_{2}$. It also leads to less heterogeneous hydrolysis of $\mathrm{N}_{2} \mathrm{O}_{5}$. Both lead to increased $\mathrm{NO}_{\mathrm{x}}$ levels that drive ozone loss around the altitude of $\mathrm{CaCO}_{3}$ injection. Another impact of the decreased sulfate is a slight decrease in PSCs. However, the comparison between the thk-dep result and the no psc result shows that the column changes due to PSC variations do not offset the ozone decrease caused by $\mathrm{NO}_{\mathrm{x}}$ increase.

\section{Discussion}

Most narrowly, this study shows that our prior work overestimated the impact of $\mathrm{CaCO}_{3}$ aerosol on ozone chemistry. The aged $\mathrm{CaCO}_{3}$ aerosol is close to unreactive with respect to gas-phase uptake reactions. As a result, these uptake coefficients produce smaller ozone response in the opposite direction than predicted in Keith et al., and thus no contribution to the restoration of column ozone. However, since $\mathrm{CaCO}_{3}$ reduces stratospheric heating and ozone depletion compared to sulfate aerosols, and since there may be methods of increasing the ozone benefit of $\mathrm{CaCO}_{3}$ by increasing surface reactivity, it is still a viable candidate for SG.

The reduced ozone response is robust under a wide range of uncertainties. To assess the impact of uncertainties in the thickness-dependent $\gamma$ parameterizations, we conduct model runs assuming upper and lower limits of the thickness-dependent uptake coefficient confidence intervals shown in Fig. 2c, d. In addition, we capture uncertainties in surface area density of the $\mathrm{CaCO}_{3}$ particles with the $10-\gamma$ and $0-\gamma$ scenarios. Neither this scenario nor the inclusion of gas-phase concentration-dependent $\gamma$ for Eqs. (2) and (3) (thk-dep + conc-dep) produce more than $1 \%$ ozone column differences anywhere as shown in Fig. 4. This is explained by the fact that the ozone response is dominated by changes in sulfate surface area, not uptake reactions of gas-phase species on $\mathrm{CaCO}_{3}$.

More generally, these results highlight the importance of considering changes in uptake coefficients due to gas-phase exposure 
when determining the impacts of solid reactive particles. Further studies should explore the uptake coefficients of other ozone related gases. The details of the physical and chemical changes from reaction with sulfate aerosols, including those that contain organics $^{34}$ are also important. Finally, there is uncertainty about how reactivity depends on the details of morphology and surface chemistry, which is important because $\mathrm{CaCO}_{3}$ aerosol could be produced by a variety of technologies ${ }^{35}$.

Our work illustrates how laboratory research can address uncertainties in stratospheric aerosol geoengineering. It is likely that there will be many other examples of novel measurements that can be accomplished with well-established experimental methods and are crucial in evaluating novel proposals that address risks posed by SG. As an illustration, the following experiments are straightforward applications of existing methods yet could be important to assessing SG risks:

Other heterogeneous reactions on $\mathrm{CaCO}_{3}$. Heterogeneous reactions of $\mathrm{ClONO}_{2}$ and $\mathrm{HOCl}$ with water and $\mathrm{HCl}$ on particle surfaces present key uncertainties of ozone response to $\mathrm{CaCO}_{3}$ geoengineering. Among these, reactions with $\mathrm{HCl}$ could be more important since the uptake coefficients of $\mathrm{ClONO}_{2}$ in the presence of $\mathrm{HCl}$ was shown to be two orders of magnitude greater than in the presence of water on solid surfaces ${ }^{5,36}$. Including an uptake coefficient of 0.02 for $\mathrm{ClONO}_{2}+\mathrm{HCl}$ (the value measured on alumina surface ${ }^{5}$ ) for both the thk-dep and thk-ind cases decreases global ozone column by $2-3 \%$ compared to cases without this reaction (Supplementary Fig. S3). Ozone decreases up to $15 \%$ below the baseline over the south pole in the thk-dep case. Further including an uptake coefficient of 0.1 for $\mathrm{HOCl}+$ $\mathrm{HCl}$ did not change the ozone columns by more than $0.5 \%$. Our results modified the ozone response estimate of Keith et al. ${ }^{1}$, but some relevant reactions are still poorly constrained by experiment. A next step would be to measure reaction rates of $\mathrm{ClONO}_{2}+\mathrm{HCl}$ on fresh and aged $\mathrm{CaCO}_{3}$ surfaces.

Optical properties of $\mathrm{CaCO}_{3}$ aerosol. The major proposed advantage of $\mathrm{CaCO}_{3}$ over sulfuric acid aerosol is that it causes less radiative heating due to less solar and IR-band absorption and thus could pose lower risk with respect to changes in dynamics, which are poorly understood ${ }^{9}$. Yet, this hypothesis is based on bulk optical properties of pure $\mathrm{CaCO}_{3}$ that may differ from aged $\mathrm{CaCO}_{3}$ aerosols in the stratosphere (e.g., surface salts could form hydrates that shift the absorption of terrestrial radiation and $\mathrm{Ca}$ $\left(\mathrm{NO}_{3}\right)_{2}$ may absorb in the UV). Well-established methods could be used to measure the real and imaginary index of refraction of aged $\mathrm{CaCO}_{3}$ powder. The aging process should include a range of stratospherically relevant processes including gas-phase reactions (as we explored in the flask experiments) and exposure to UV radiations.

Ice nucleating properties. Aerosols used in SG may impact cirrus cloud formation once they descend into the upper troposphere ${ }^{37,38}$. The ice nucleating properties are important in determining impacts of the sedimented aerosols on cirrus clouds. In addition, ice may nucleate onto the $\mathrm{CaCO}_{3}$ particles in the Antarctic winter under PSC conditions, affecting PSC formation. Experiments using a variety of laboratory experimental techniques ${ }^{39}$ could test ice nucleating properties on $\mathrm{CaCO}_{3}$ powder that had been prepared under the range of conditions described in the prior paragraph. For example, Cziczo et al. ${ }^{4}$ has tested ice nucleating properties of $\mathrm{CaCO}_{3}, \mathrm{CaSO}_{4}$, and $\mathrm{Ca}\left(\mathrm{NO}_{3}\right)_{2}$ and found that they can cause significant changes to cirrus clouds absent of natural ice nucleating particles ${ }^{4}$.
This study may have lessons for management of solar geoengineering research. Sound estimates of SG's risks and efficacy will require experiments and models. Current estimates are almost entirely based on large-scale modeling. Models are crucial, but overreliance on models may encourage overconfidence when users ignore the simplifications hidden in their assumptions. Empirical methods are needed to help reduce uncertainty. Models can explore how results depend on uncertainty in parameters to motivate experimental research which, in turn, can provide better constraints on parameters used in models. The back-and-forth between the experimental and modeling communities is essential for environmental science. The complexity of experimental results like these may serve as a useful reminder of the deep uncertainties underlying predictions about the consequences of solar geoengineering.

\section{Methods}

Gas flow system and flow tube. All gas tanks are purchased from Airgas except for the $\mathrm{SF}_{6}$ gas (Praxair, research grade). The nitrogen gas is ultra-high purity, and the $\mathrm{HCl}$ gas is a $1 \%$ blend in nitrogen. The nitric acid is generated from a permeation tube (KIN-TEK Trace Source Refillable permeation tube with a target emission rate of, $\mathrm{ng} / \mathrm{min}$ at $50^{\circ} \mathrm{C}$ ). When doing experiments, we operate the permeation tube at $20^{\circ} \mathrm{C}$ and calibrated the emission rate using the mass spectrometer.

The flow tube is jacketed with a length of $1 \mathrm{~m}$ and an inner diameter of $26 \mathrm{~mm}$. The insert has an inner diameter of $22 \mathrm{~mm}$, wall thickness of $1 \mathrm{~mm}$, and length of $22 \mathrm{~cm}$. The cooling was done by circulating an ethanol-dry ice mixture through the jacket. The temperature of the gas stream is monitored by three K-type thermocouples at the two ends and the middle of the flow tube. The temperature gradient of a typical experiment through the flow tube is $1-2 \mathrm{~K}$. For all the flowtube experiments, the flowtube temperature was controlled at $215 \mathrm{~K}$ and the pressure was 1.7 Torr. Since only dry gas streams are used in the flowtube experiments, and the reactive gas streams pass through a $\sim 20 \mathrm{~cm}$ quartz tubing at $215 \mathrm{~K}$ before reacting with particles, we treat the water vapor content in the experimental region to be 0 .

$\mathrm{ClONO}_{\mathbf{2}}$ Synthesis. The $\mathrm{ClONO}_{2}$ synthesis consists of three steps:

$$
\begin{gathered}
\mathrm{Cl}_{2} \stackrel{\mathrm{RF} \text { plasma }}{\longrightarrow} 2 \mathrm{Cl} . \\
\mathrm{Cl}+\mathrm{O}_{3} \rightarrow \mathrm{ClO} . \\
\mathrm{ClO}+\mathrm{NO}_{2} \rightarrow \mathrm{ClONO}_{2} .
\end{gathered}
$$

The gas tanks are all purchased from Airgas (Ar: $\mathrm{HP}$ grade, $\mathrm{O}_{2}$ : UHP grade, $\mathrm{Cl}_{2}$ and $\mathrm{NO}_{2}: 1 \%$ blend in nitrogen). The RF plasma is generated by a Technical Research and Manufacturing Inc. DBS301 RF generator with a frequency range of $0.125-0.25 \mathrm{GHz}$. The Power output is measured by a Bird 43 General Purpose Wattmeter and is tuned to be between 15 and $40 \mathrm{~W}$ during operation. The ozone is generated from an A2Z Ozone MP 1000 ozone generator. The ozone concentration as measured by an ozone meter is $1.5 \%$.

The synthesis conditions were simulated in a box model to guide selections of design parameters that resulted in the highest $\mathrm{ClONO}_{2}$ yield. A quartz tube acts both as an RF cavity for generating the chlorine radical and as a mixing region for the combination of $\mathrm{ClO}$ and $\mathrm{NO}_{2}$. The length of the quartz tube is $70 \mathrm{~cm}$. The distance between the two vertical flanges is $40 \mathrm{~cm}$. The outer diameter is $1 / 2 \mathrm{in}$. and the inner diameter is $1.01 \mathrm{~cm}$. We assumed no radical remains after the cold trap because the quartz wool in the cold trap provides a large surface area for them to recombine or otherwise react.

After $\mathrm{ClONO}_{2}$ is synthesized, it is collected and purified in a cold trap cooled by a cold jacket where chilled nitrogen gas flows through. The concentration of the effluent $\mathrm{ClONO}_{2}$ is measured through absorption spectroscopy in a quartz cell with an absorption length of $99.14 \mathrm{~cm}$. Absorption spectra in the $200-295 \mathrm{~nm}$ region were acquired using a fiber-coupled Ocean Optics USB4000 UV-Vis spectrometer (10- $\mu \mathrm{m}$ slit width, 200-400 nm 5 grating) illuminated by a Hamamatsu L2D2 deuterium lamp. The concentration of $\mathrm{ClONO}_{2}$ is then calculated based on the absorption cross section data in the JPL database ${ }^{40}$. It is determined to be about $75 \mathrm{ppm}$ under typical synthesis conditions.

Material and preparation for the flow tube experiment. The calcite particles is purchased from American Elements with a manufacture-reported average diameter of $200 \mathrm{~nm}$. The Brunauer-Emmett-Teller (BET) surface area of these particles is measured by a Quantacrome Monosorb instrument using $\mathrm{N}_{2}$ as the adsorption gas The BET surface area reported was $14.8 \pm 0.5 \mathrm{~m}^{2} / \mathrm{g}$. We also measured the BET surface area of samples after processing by isopropyl alcohol (IPA) and found that IPA processing did not change the BET surface area. The $\mathrm{NaCl}$ particles (puriss. p.a., $\geq 99.5 \%$, powder or crystals) used are purchased from Sigma Aldrich. To increase the amount of surface area per unit mass, the particles are then processed 
in a Retsch PM100 planetary ball mill. The BET surface area of the resulting $\mathrm{NaCl}$ particles is measured by a Beckman Coulter SA 3100 Surface Area Analyzer using $\mathrm{He}$ as the absorption gas. The BET surface area is $0.051 \pm 0.005 \mathrm{~m}^{2} / \mathrm{g}$ for $\mathrm{NaCl}$ before milling, and $0.38 \pm 0.05 \mathrm{~m}^{2} / \mathrm{g}$ after milling.

Before the experiment, the $\mathrm{CaCO}_{3}$ particles are deposited on the insert from a suspension of $\mathrm{CaCO}_{3}$ in IPA. A known volume of a suspension with known mass concentration of $\mathrm{CaCO}_{3}$ is pipetted into the insert. The insert is heated at roughly $60^{\circ} \mathrm{C}$ and rotated to spread the particles evenly over the insert while the IPA evaporates. This process is repeated until a desired amount of $\mathrm{CaCO}_{3}$ is deposited on the insert. The insert is then heated in an oven at $250^{\circ} \mathrm{C}$ for roughly $30 \mathrm{~min}$ to drive off any excess IPA. A similar deposition method has been used to prepare inserts for other flow tube experiments ${ }^{24}$. Typically, the insert is deposited with $\sim 2.5$ layers of particles. For uptake experiments on $\mathrm{CaCl}_{2}$, the $\mathrm{CaCO}_{3}$ insert is exposed to about 70 Torr of $\mathrm{HCl}$ vapor in the flow tube for at least $8 \mathrm{hrs}$ at room temperature forming a layer of $\mathrm{CaCl}_{2}$. The insert is then used directly for the uptake experiment without being exposed to room air after the flow tube is pumped down. This method is used because $\mathrm{CaCl}_{2}$ is hygroscopic and cannot be purchased in its dehydrated form. We confirmed that this produced at least $2 \mathrm{~nm}$ of $\mathrm{CaCl}_{2}$ using the same procedure for determining chloride content as for the longterm uptake experiment. The $\mathrm{NaCl}$ particle insert was prepared in the same way as the $\mathrm{CaCO}_{3}$ insert. Before each uptake experiment, the insert is placed into the flow tube which is pumped down to $\sim 60 \mathrm{mTorr}$ for at least $2 \mathrm{~h}$ before an uptake experiment starts. According to Santschi and Rossi ${ }^{21}$, this is sufficient to drive off all but strongly-bound surface water. It is possible that some IPA molecules could adsorb to the $\mathrm{CaCO}_{3}$ surface even after the oven and vacuum processing. However, we expect this effect to be small since heating has been shown to be effective at removing adsorbed water from $\mathrm{CaCO}_{3}$ surfaces by Santchi and Rossi, and IPA is more volatile than water.

Flow tube experiment. The uptake experiment design follows Molina et al. but differs in two respects. First, instead of moving the injector with respect to the stationary insert and flow tube, the insert is moved relative to the stationary injector and flow tube. Four magnets attached to the injector rod and the insert allow for this configuration. This eliminates condensation on the injector when it retracts from the low temperature region of the flow tube without having to heat the injector. It also eliminates the possibility of gas leaks into the flow tube due to mechanical movement of the injector relative to the vacuum seal. Second, instead of electron impact ionization, ions are produced by chemical ionization by $\mathrm{SF}_{6}{ }^{-}$as outlined in Huey et al. ${ }^{41}$.

An alternative method used in the literature to measure heterogeneous uptake coefficients is the aerosol flow tube experiment, where the aerosols are dispersed in a gas stream and flow with the carrier gas ${ }^{42}$. This method eliminates issues with gas-phase diffusion limitations and gas-transfer limitations within the particle layers. However, one key disadvantage of aerosol flow tube experiment compared to our coated wall flow tube experiment is that it is difficult to extend the residence time of particles in the reaction region beyond tens of seconds. As shown in the results section, reactive uptake coefficients on $\mathrm{CaCO}_{3}$ particles continue to change for more than $10 \mathrm{~min}$ due to gradual surface saturation. Aerosol flow tube experiments cannot capture changes in this process. To overcome the issue with gas phase diffusion limitation with the coated wall flow tube experiments, we applied a correction to the uptake coefficients as outlined in the following section. This correction was small due to the low uptake coefficients measured in our experiments. In addition, to probe the effect of gas transfer limitations within the particle layers, we measured uptake coefficients of Eq. (2) for different $\mathrm{CaCO}_{3}$ layer thickness and found that the uptake coefficients measured at the semi steady state were $2 \pm 1.5 \times 10^{-4}, 4 \pm 2 \times 10^{-4}$, and $3 \pm 2 \times 10^{-4}$ for $0.5,1.5$, and 2.5 layers of coated $\mathrm{CaCO}_{3}$ thickness on the insert. These are similar to values reported by Santschi and Rossi $^{21}$ for cleaved $\mathrm{CaCO}_{3}$ marbles and did not differ with layer thickness, showing that the diffusion limitations within the particle layer was not a concern for our experiments. Another way to validate this result is to calculate the diffusion-reaction length scale. Assuming a pseudo first-order reaction and using Fick's Second Law, we can write out the reactive concentration at steady state as where $C$ is the concentration of the reactive gas, $t$ is the reaction time, $D$ is the inter-diffusion constant $\left(45.44 \mathrm{~cm}^{2} / \mathrm{s}\right.$ for $\mathrm{HCl}$ in $\mathrm{N}_{2}$ at $213 \mathrm{~K}$ and $\left.1.67 \mathrm{Torr}\right)$, and $\mathrm{k}$ is the pseudo first-order reaction constant. For the purpose of this calculation, $k$ is related to the uptake coefficient $\gamma$ by $k=\gamma A_{\mathrm{v}} \omega$, where $A_{\mathrm{v}}$ is the volume-normalized particle surface area (for calcite, $4.02 \times 10^{7} \mathrm{~m}^{2} / \mathrm{m}^{3}$ based on the BET surface area measurement), and $\omega$ is the average molecular velocity. Taking $\gamma$ to be $5 \times 10^{-3}$ (high end of the values in our measurement), the diffusion length scale is then and is calculated as $45 \mu \mathrm{m}$. Correcting for the porosity of the particle stack does not change the order of magnitude of this length. The length is much larger than the average particle layer thickness $(<1 \mu \mathrm{m})$ and provides a theoretical justification for why the measured $\gamma$ is not influenced by the thickness of the particle layer.

Uptake coefficient calculation. The uptake coefficients are calculated based on methods in Knopf et al. ${ }^{26}$. First, $\gamma_{\text {eff }}$ the effective uptake coefficient, is calculated from the experimental observations assuming first-order reaction kinetics as:

$$
\gamma_{\text {eff }}=\frac{D_{\text {tube }}}{\omega_{x} t} \ln \left(\frac{[X]_{g, 0}}{[X]_{g}}\right),
$$

where $D_{\text {tube }}$ is the tube diameter, $\omega_{x}$ is the thermal molecular velocity, $t$ is interaction time between gas and particles, $[X]_{g, 0}$ and $[X]_{g}$ are concentrations of the uptaken gas $\mathrm{X}$ at the entrance and exit of the inset respectively. In the experiments these are measured as concentrations before and after the insert is exposed to the reactive gas stream. $[X]_{g, 0} /[X]_{g}$ is the penetration ratio. The gas phase diffusion effects are then corrected to calculate the actual uptake coefficient $\gamma$ as:

$$
\gamma=C \frac{\gamma_{\text {eff }}}{1-\gamma_{\text {eff }} \frac{3}{2 N_{S h w}^{e f f} K n_{X}}},
$$

where $C$ is the ratio between the geometric area of the insert and the BET surface area of the particles, $N^{e f f} f_{S h w}$ is the effective Sherwood number, and $K n_{X}$ is the Knudsen number following the definition in Knopf et al. As outlined in Knopf et al., the gas phase correction factor $\left(\gamma_{\text {eff }} \gamma\right)$ decreases with increasing uptake coefficients. Under our experimental conditions, this correction factor ranges from 1 to $5 \%$.

Uptake experiments were first performed on a blank quartz insert using the same procedure as for the uptake experiments to determine the baseline uptake. No significant uptake was observed for $\mathrm{HCl}$ and $\mathrm{ClONO}_{2}$. However, $\mathrm{HNO}_{3}$ showed a large uptake signature. The uptake signal of this baseline uptake at steady state was extracted from these experiments and subtracted from the uptake signals when calculating the uptake coefficients.

Flask experiment procedures. $0.1 \mathrm{~g}$ of $\mathrm{CaCO}_{3}$ particles are deposited at the bottom of a glass vessel. A mixture of $\mathrm{HCl}$ gas and $\mathrm{N}_{2}$ gas controlled by upstream mass flow controllers flows through the bottle, allowing $\mathrm{HCl}$ vapor to react with the particles. The pressure of the bottle is controlled by a check valve at roughly ambient pressure. Before reaction starts, the vessel is secured in a box of dry ice for roughly $10 \mathrm{~min}$, so its temperature equilibrates. During this time, dry nitrogen gas flows through the bottle to drive away room air left in the bottle. After the reaction process completes and the $\mathrm{HCl}$ gas flow is turned off, the $\mathrm{N}_{2}$ gas flow continues for an extra 10 min to allow all $\mathrm{HCl}$ gas metered into the flow system to pass through the reaction vessel. For longer-term reactions, the dry ice is replenished roughly twice per day to maintain the temperature of the bottle. After the reaction, the particles are suspended in $10 \mathrm{~mL}$ of milli-q water so the $\mathrm{CaCl}_{2}$ on the surface would dissolve in the water. The suspension is then filtered through a $20 \mathrm{~nm}$ syringe filter. The $\mathrm{Cl}^{-}$concentration in the resulting solution is measured by a Cole-Parmer Combination Ion-Selective Electrode for chloride ions. The electrode is calibrated each time before a measurement using known concentrations of $\mathrm{CaCl}_{2}$ solutions that bracket the measured $\mathrm{Cl}^{-}$concentration range. The thickness of the $\mathrm{CaCl}_{2}$ layer formed is calculated using the BET surface area, the bulk density of $\mathrm{CaCl}_{2}$, and the total amount of $\mathrm{Cl}$ ions reacted with the $\mathrm{CaCO}_{3}$ particles.

Error characterization. For the flow tube experiments, random errors in the uptake coefficients arise from uncertainties in various physical measurements and the MS signal noise. To first order, random errors correspond to the partial differential of uptake coefficient $(\gamma)$ with respect to uncertainties of the respective factors. We considered uncertainties arising from measurements based on instrument specifications (temperature: $\pm 5 \mathrm{~K}$, pressure: \pm 5 mTorr, flow: $\pm 3 \mathrm{sccm}$, and BET surface area: $\pm 0.5 \mathrm{~m}^{2} / \mathrm{g}$ ). These uncertainties correspond to roughly $30 \%$ of total uncertainties across the range of $y$ values we measured (the BET surface area measurements account for $90 \%$ of this uncertainty), and the MS signal noise account for the remaining $70 \%$.

For the flask experiment measurements, random errors come mainly from the precision of the ion-selective electrode used to measure the chloride ion concentration ( $2 \%$ of the measured voltage). Another source of error is the dead volume in the glass vessel, which takes time for the influent $\mathrm{HCl}-\mathrm{N}_{2}$ mixture to displace at the start of the reaction. To account for this effect, we included an uncertainty term that is equivalent to the time that the influent gas fully displaces the dead volume $(\sim 10 \mathrm{~s})$. This effect is negligible for longer period reactions (>1 min) but has a significant effect for the shorter-term reactions.

Modeling method. In order to probe the impact on global stratospheric ozone, we conduct similar simulations as Keith et al. ${ }^{1}$ using the AER 2-D chemical transportaerosol model. All model specifications follow that study except for the uptake coefficients to isolate the impact of uptake coefficients measured in this work. We investigate the highest $\mathrm{CaCO}_{3}$ emission rate in that study with $5.6 \mathrm{Tg} \mathrm{yr}^{-1}$ of uniform $\mathrm{CaCO}_{3}$ emission between $30^{\circ} \mathrm{S}$ and $30^{\circ} \mathrm{N}$ and between 20 and $25 \mathrm{~km}$. This produces roughly $2 \mathrm{~W} \mathrm{~m}^{-2}$ of global radiative forcing (RF). $\mathrm{CaCO}_{3}$-related reactions that are included in the model consist of Eqs. (1)-(4) and coagulation of sulfate aerosols with $\mathrm{CaCO}_{3}$ particles. The coagulation was treated in the same way as Keith et al. ${ }^{1}$, assuming liquid sulfate reacts with $\mathrm{CaCO}_{3}$ to form $\mathrm{CaSO}_{4}$ instantaneously once sulfate aerosols coagulate with $\mathrm{CaCO}_{3}$ aerosols. Future atmosphere trace gases for 2040 conditions are taken from RPC 6.0, providing 2.3 ppbv of $\mathrm{Cl}_{\mathrm{y}}$ in the upper stratosphere but with temperature and circulation from a 1978-2004 climatology.

\section{Data availability}

The modeling and experimental data that support the findings of this study are available in Harvard DataVerse with the identifier https://doi.org/10.7910/DVN/FHISDB. 


\section{Code availability}

The computer code used to support the findings of this study are available in Harvard DataVerse with the identifier doi.org/10.7910/DVN/FHISDB.

Received: 12 August 2020; Accepted: 6 November 2020;

Published online: 15 December 2020

\section{References}

1. Keith, D. W., Weisenstein, D. K., Dykema, J. A. \& Keutsch, F. N. Stratospheric solar geoengineering without ozone loss. Proc. Natl Acad. Sci. 113, 14910-14914 (2016).

2. Macnaghten, P. \& Owen, R. Environmental science: good governance for geoengineering. Nature 479, 293-293 (2011).

3. Tang, M. J. et al. Heterogeneous reaction of $\mathrm{N}_{2} \mathrm{O}_{5}$ with airborne $\mathrm{TiO}_{2}$ particles and its implication for stratospheric particle injection. Atmos. Chem. Phys. 14, 6035-6048 (2014).

4. Cziczo, D. J., Wolf, M. J., Gasparini, B., Münch, S. \& Lohmann, U. Unanticipated side effects of stratospheric albedo modification proposals due to aerosol composition and phase. Sci. Rep. 9, 1-7 (2019).

5. Molina, M., Molina, L., Zhang, R., Meads, R. \& Spencer, D. The reaction of $\mathrm{C}_{10} \mathrm{NO}_{2}$ with $\mathrm{HCl}$ on aluminum oxide. Geophys. Res. Lett. 24, 1619-1622 (1997).

6. Robock, A., Macmartin, D. G., Duren, R. \& Christensen, M. W. Studying geoengineering with natural and anthropogenic analogs. Clim. Change, https://doi.org/10.1007/s10584-013-0777-5 (2013).

7. Smith, W. \& Wagner, G. Stratospheric aerosol injection tactics and costs in the first 15 years of deployment. Environ. Res. Lett. 13, 124001 (2018).

8. Smith, J. P., Dykema, J. A. \& Keith, D. W. Production of sulfates onboard an aircraft: implications for the cost and feasibility of stratospheric solar geoengineering. Earth Sp. Sci. 5, 150-162 (2018).

9. Dykema, J. A., Keith, D. W. \& Keutsch, F. N. Improved aerosol radiative properties as a foundation for solar geoengineering risk assessment. Geophys. Res. Lett. 43, 7758-7766 (2016).

10. Jones, A. C., Haywood, J. M. \& Jones, A. Climatic impacts of stratospheric geoengineering with sulfate, black carbon and titania injection. Atmos. Chem. Phys. 16, 2843-2862 (2016).

11. Ferraro, A. J., Highwood, E. J. \& Charlton-Perez, A. J. Stratospheric heating by potential geoengineering aerosols. Geophys. Res. Lett. 38, 1-6 (2011).

12. Pope, F. D. et al. Stratospheric aerosol particles and solar-radiation management. Nat. Clim. Chang. 2, 713-719 (2012).

13. Tilmes, S., Müller, R. \& Salawitch, R. The sensitivity of polar ozone depletion to proposed geoengineering schemes. Science (80-.) 320, 1201-1204 (2008).

14. Pitari, G. et al. Stratospheric ozone response to sulfate geoengineering: results from the Geoengineering Model Intercomparison Project (GeoMIP). J. Geophys. Res. Atmos. 119, 2629-2653 (2014).

15. Heckendorn, P. et al. The impact of geoengineering aerosols on stratospheric temperature and ozone. Environ. Res. Lett. 4, 045108 (2009).

16. Richter, J. H. et al. Stratospheric dynamical response and ozone feedbacks in the presence of $\mathrm{SO}_{2}$ injections. J. Geophys. Res. Atmos. https://doi.org/10.1002/ 2017JD026912 (2017).

17. Teller, E., Wood, L. \& Hyde, R. Global warming and ice ages: I. Prospects for physics-based modulation of global change. In: 22nd Proceedings of International Seminar on Planetary Emergencies (1997).

18. Weisenstein, D. K., Keith, D. W. \& Dykema, J. A. Solar geoengineering using solid aerosol in the stratosphere. Atmos. Chem. Phys. 15, 11835-11859 (2015).

19. Carr, F. P. \& Frederick, D. K. Calcium Carbonate. In Kirk-Othmer Encyclopedia of Chemical Technology, https://doi.org/10.1002/0471238961.0301120303 011818.a01.pub3 (2014)

20. Solomon, S. Stratospheric ozone depletion: a review of concepts and history. Rev. Geophys. 37, 275 (1999).

21. Santschi, C. \& Rossi, M. J. Uptake of $\mathrm{CO}_{2}, \mathrm{SO}_{2}, \mathrm{HNO}_{3}$ and $\mathrm{HCl}$ on calcite $\left(\mathrm{CaCO}_{3}\right)$ at $300 \mathrm{~K}$ : mechanism and the role of adsorbed water. J. Phys. Chem. A 110, 6789-6802 (2006).

22. Crowley, J. N. et al. Evaluated kinetic and photochemical data for atmospheric chemistry: volume $\mathrm{V}-$ heterogeneous reactions on solid substrates. Atmos. Chem. Phys. 10, 9059-9223 (2010).

23. Davies, J. A. \& Cox, R. A. Kinetics of the heterogeneous reaction of $\mathrm{HNO}_{3}$ with NaCl: effect of water vapor. J. Phys. Chem. A 102, 7631-7642 (1998).

24. Schmidt, C. M., Weitz, E. \& Geiger, F. M. Interaction of the indoor air pollutant acetone with degussa p25 tio 2 studied by chemical ionization mass spectrometry. Langmuir 22, 9642-9650 (2006).

25. Gebel, M. E. \& Finlayson-Pitts, B. J. Uptake and reaction of $\mathrm{ClONO}_{2}$ on $\mathrm{NaCl}$ and synthetic sea salt. J. Phys. Chem. A 105, 5178-5187 (2001).

26. Knopf, D. A., Pöschl, U. \& Shiraiwa, M. Radial diffusion and penetration of gas molecules and aerosol particles through laminar flow reactors, denuders, and sampling tubes. Anal. Chem. 87, 3746-3754 (2015).
27. Al-Hosney, H. A. \& Grassian, V. H. Water, sulfur dioxide and nitric acid adsorption on calcium carbonate: a transmission and ATR-FTIR study. Phys. Chem. Chem. Phys. 7, 1266-1276 (2005).

28. Kirkby, N. F., Seville, J. P. K. \& Clift, R. Alteration with reaction progress of the rate limiting step for solid-gas reactions of Ca-compounds with HCI. Chem. Eng. Sci. 50, 2017-2027 (2017).

29. Antonioni, G., Pozzo, A. D., Guglielmi, D. \& Tugnoli, A. Enhanced modelling of heterogeneous gas-solid reactions in acid gas removal dry processes. Chem. Eng. Sci. 148, 140-154 (2016).

30. Vlasenko, A., Huthwelker, T., Gäggeler, H. W. \& Ammann, M. Kinetics of the heterogeneous reaction of nitric acid with mineral dust particles: an aerosol flowtube study. Phys. Chem. Chem. Phys. 11, 7921-7930 (2009).

31. Huthwelker, T., Malmström, M. E., Helleis, F., Moortgat, G. K. \& Peter, T. Kinetics of $\mathrm{HCl}$ uptake on ice at 190 and $203 \mathrm{~K}$ : Implications for the microphysics of the uptake process. J. Phys. Chem. A 108, 6302-6318 (2004).

32. Huthwelker, T., Malmstro, M. E., Helleis, F., Moortgat, G. K. \& Peter, T. Kinetics of $\mathrm{HCl}$ uptake on ice at 190 and $203 \mathrm{~K}$ : implications for the microphysics of the uptake process. 6302-6318, https://doi.org/10.1021/ jp0309623 (2004).

33. Diciccio, T. J. \& Efron, B. Bootstrap confidence intervals. Stat. Sci 11, 189-228 (1996).

34. Murphy, D. M., Froyd, K. D., Schwarz, J. P. \& Wilson, J. C. Observations of the chemical composition of stratospheric aerosol particles. Q. J. R. Meteorol. Soc. 140, 1269-1278 (2014).

35. Boyjoo, Y., Pareek, V. K. \& Liu, J. Synthesis of micro and nano-sized calcium carbonate particles and their applications. J. Mater. Chem. A 2, 14270 (2014).

36. Tang, M. J. et al. Heterogeneous reaction of $\mathrm{ClONO}_{2}$ with $\mathrm{TiO}_{2}$ and $\mathrm{SiO}_{2}$ aerosol particles: implications for stratospheric particle injection for climate engin. Atmos. Chem. Phys. Discuss. 1-42, https://doi.org/10.5194/acp-2016756 (2016).

37. Kuebbeler, M., Lohmann, U. \& Feichter, J. Effects of stratospheric sulfate aerosol geo-engineering on cirrus clouds. Geophys. Res. Lett. 39, 1-5 (2012).

38. Muri, H., Kristjánsson, J. E., Storelvmo, T. \& Pfeffer, M. A. The climatic effects of modifying cirrus clouds in a climate engineering framework. J. Geophys. Res. 119, 4174-4191 (2014).

39. Hoose, C. \& Möhler, O. Heterogeneous ice nucleation on atmospheric aerosols: a review of results from laboratory experiments. Atmos. Chem. Phys. 12, 9817-9854 (2012).

40. Sander, S. P. et al. Chemical kinetics and photochemical data for use in atmospheric studies, evaluation no. 17. JPL Publication 10-6, (Pasadena, CA: Jet Propulsion Laboratory, 2011) http://jpldataeval.jpl.nasa.gov.

41. Huey, L. G., Hanson, D. R. \& Howard, C. J. Reactions of SF6- and I- with atmospheric trace gases. J. Phys. Chem. 99, 5001-5008 (1995).

42. Kolb, C. E. et al. An overview of current issues in the uptake of atmospheric trace gases by aerosols and clouds. Atmos. Chem. Phys. 10, 10561-10605 (2010).

\section{Acknowledgements}

This work was sponsored by Star-Friedman Challenge for Promising Scientific Research and Fund for Innovative Climate and Energy Research. We thank Dr. Faye McNeill for critical reading of an early draft of the experimental section.

\section{Author contributions}

Z.D., D.K.W., F.N.K., and D.W.K. designed research; Z.D., D.K.W., F.N.K., and D.W.K. performed research; Z.D. conducted laboratory experiments; D.K.W. performed chemical transport modeling; Z.D., D.K.W., F.N.K., and D.W.K. analyzed data; and Z.D., D.K.W., F.N.K., and D.W.K. wrote the paper.

\section{Competing interests}

The authors declare no competing interests.

\section{Additional information}

Supplementary information is available for this paper at https://doi.org/10.1038/s43247020-00058-7.

Correspondence and requests for materials should be addressed to Z.D.

Peer review information Primary handling editor: Teresa Ortner.

Reprints and permission information is available at http://www.nature.com/reprints

Publisher's note Springer Nature remains neutral with regard to jurisdictional claims in published maps and institutional affiliations. 
(c) (i) Open Access This article is licensed under a Creative Commons Attribution 4.0 International License, which permits use, sharing, adaptation, distribution and reproduction in any medium or format, as long as you give appropriate credit to the original author(s) and the source, provide a link to the Creative Commons license, and indicate if changes were made. The images or other third party material in this article are included in the article's Creative Commons license, unless indicated otherwise in a credit line to the material. If material is not included in the article's Creative Commons license and your intended use is not permitted by statutory regulation or exceeds the permitted use, you will need to obtain permission directly from the copyright holder. To view a copy of this license, visit http://creativecommons.org/ licenses/by/4.0/.

(C) The Author(s) 2020 